\title{
Metaphorical Analysis of the Image of Water in Beloved
}

\author{
Gengqing Chen ${ }^{1} \&$ Weiwei Wang ${ }^{1}$ \\ ${ }^{1}$ Qinhuangdao Branch of Northeast Petroleum University, Qinhuangdao, China \\ Correspondence: Gengqing Chen, Department of Basic Courses, Qinhuangdao Branch of Northeast Petroleum \\ University, 550, West Hebei Street, Haigang District, 066004, Qinhuangdao, Hebei, China. E-mail: \\ steviv2003@gmail.com
}

Received: March 11, 2014 Accepted: May 29, 2014 Online Published: July 30, 2014

doi: $10.5539 /$ ijel.v4n4p93

URL: http://dx.doi.org/10.5539/ijel.v4n4p93

\begin{abstract}
Toni Morrison is the first black woman winning Nobel Prize for literature. She always focuses on the living conditions and spiritual world of black people as well as the mental process and unyielding struggle under such conditions. Her fifth novel, Beloved has won wide recognition since its publication. With superb writing techniques and full emotion, she shapes the image of the black characters vividly.

One of the salient characteristics is the application of metaphorical language. As the language tool and main thread of the novel, metaphors not only strengthen the artistic effects of the work, but also contribute significantly to the exploration of its deep themes and dense implications.

Based on Conceptual Metaphor Theory (CMT) put forward by Lakoff \& Johnson and Conceptual Blending Theory (CBT) by Fauconnier \& Turner, the thesis aims to analyze the metaphors of the novel. Traditional research of metaphors focuses on the rhetoric function and artistic effect, while CMT and CBT do the job from the level of the cognitive function of metaphors, thus providing us with better semantic and contextual understanding.

The article is composed of five parts. The first part gives a brief introduction to Toni Morrison and her works. The second part introduces the development and significance of CMT and CBT. In the third part, the author tries to analyze the metaphorical meanings of the governing image of water. Closely interwoven with each other, these metaphors reveal the evil of slavery and the self-redemption of black spirit as well as forming a huge network. Therefore, the fifth part summarizes the case studies of the previous parts and analyzes the systematicity of metaphors to unveil the "huge iceberg" behind it, thus demonstrating the writing intentions and keen insight of the writer in hope that the thesis will offer a new perspective to understand and appreciate the novel Beloved.
\end{abstract}

Keywords: conceptual metaphor, conceptual blending, Toni Morrison, Beloved, redemption

\section{Introduction}

Toni Morrison, born in Lorain of Ohio on February 18, 1931, is a well-known African-American novelist, editor and professor. Toni Morrison is the first African-American woman to win Nobel Prize. She is devoted to writing the experience and psychology of the black people who are suffering deeply from the traumas of slavery and still considered as a marginalized group in American now. The black women are always one of her focuses. She once said "I write for black women. We are not addressing the men, as some white female writers do. We are not attacking each other, as both black and white men do. Black women writers look at things in an unforgiving/loving way. They are writing to repossess, re-name, re-own.” (McKay, 1988).

The novel Beloved which is considered as a novel of trauma and psychological conflict, is one of Morrison's most extraordinary work. In the novel, the heroin Sethe escapes from the dehumanized life in the plantation Sweet Home to seek a free life in 124, while the hope is ruined when the slaver come to capture her. In order to save the children from the evil of slavery, Sethe kills one of her child Beloved with a handsaw. After years, Beloved comes back to the living world in human body and reclaims the mother's love from Sethe. At last, Beloved disappears from their life and all the characters in the novel achieve their rebirth. It seems a ghost story at the first glance and its gothic style as well as fragmentary structure makes it hard to understand. While it is a true record of the pains and tears of the black people under slavery, at the same time, it is a laud of the spirit of the black who cherish their identities and reconstruct themselves under the oppression of the white. 
A large number of studies on Morrison and her works appear each year from diverse perspectives including her cultural consciousness, historical consciousness, racial concern and feminist standing point, yet there is still not a comprehensive and systematic study of the metaphors in Beloved from the perspective of cognitive linguistics. In an interview, Toni Morrison talks about the attention she pays to metaphors in her novel: In language all you have are those 26 letters, some punctuation and some paper. So you have to do everything with just that. A metaphor is a way of seeing something, either familiar or unfamiliar, in a way that you can grasp it. (Bell, 1983) It is noteworthy that one of the remarkable characteristics of the novel is its metaphorical language and those metaphors with deep and hidden meanings embedded in the novel along with the development of plots. The analysis based on conceptual metaphor theory and conceptual blending theory will reveal the hidden forces in the conceptualization of the writer. It also highlights the connections and coherence between the metaphors to form a network and explore the structure at macro level, thus providing better appreciation of the novel.

The article is a tentative study of the metaphors in Beloved from the perspective of cognitive linguistics in hope that it will shed some light on the interpretation of metaphors and open up a new way to the research on Toni Morrison's works.

\section{Theoretical Preliminaries}

\subsection{Conceptual Metaphor Theory (CMT)}

In 1980, the study of metaphor ushered in a new era with the publication of Metaphors We Live By co-authored by Lakoff \& Johnson. They claim that "Metaphor is pervasive in everyday life, not just in language but in thought and action; our ordinary conceptual system, in terms of which we both think and act, is fundamentally metaphorical in nature." (Lakoff \& Johnson, 1980). In this book, they explore the nature of language as well as metaphor and testify the close connection between language and cognitive structure of metaphors through a large number of examples. They define these metaphors as conceptual metaphorical concepts, such as "Time is money.", "Life is jouney.", "Life is play.", "Argument is war.".

At the same time, systematicity of conceptual metaphor is another focus. Based on the previous studies on materials, they assert that metaphorical expressions in our language are tied to metaphorical concepts in a systematic way and the conceptual system influences our language and way of thinking.

\subsection{Conceptual Blending Theory (CBT)}

Conceptual blending theory is considered as a refinement of conceptual metaphor theory that is put forward by Fauconnier \& Turner. This theory develops on the basis of "mental space". The theory of mental space is an important part of linguistics and the definition come into being in their first book Mental Space published in 1985. "Mental spaces are small conceptual packets constructed as we think and talk, for purposes of local understanding and action. Mental spaces are very partial assemblies containing elements, and structured by frames and cognitive models. They are interconnected, and can be modified as thought and discourse unfold. Mental spaces can be used generally to model dynamical mappings in thought and language."(Fauconnier \& Turner, 1996).

The notion of "conceptual blending" is first proposed by Fauconnier in the book Mapping in Thought and Language in 1997. Conceptual blending is a systematic elaboration on the projection among the spaces and the interaction during the process of thought and action to reveal the cognitive iceberg behind the on-line construction of language meaning. According to Fauconnier \& Turner, four spaces combined form the cognitive operation of conceptual blending. There are at least two INPUT spaces with a partial cross-space mapping between them. The shared structure of two INPUT spaces is represented in GENERIC space in the network of conceptual integration and integrate into another space, the BLENDED space which inherits partial structure from the input spaces has its own emergent structure.

Compared with conceptual metaphor theory, conceptual blending theory focuses on the on-line construction of meaning. Therefore, "Blending is a dynamic process that can happen repeatedly in the same network."(Fauconnier \& Turner, 1996). And its proposal that the construction of meanings lie mainly in the blending spaces is a landmark in the field of linguistic study. CMT and CBT also differ in their focuses that the former for entrenched conceptual relationships and the latter for novel conceptualizations. Conceptual blending theory is mainly employed to elaborate meaning construction and reasoning system of the "on-line metaphorical process", therefore has the mighty explanatory power of metaphor to solve the mismatches that could not be explained by conceptual metaphor theory. A case will be offered to show the advantages of CBT. This surgeon is a butcher. The first look will reveal the direct projection from the source domain of animal, slaughter and slaughterhouse to the target domain of patient, cure and operation room But a close look will reveal the failure of 
the expressions that "The surgeon is incapable." because the relation between method-result is not matched. According to CBT, we could extract from the input of operation the elements of patient, doctor and others while extract from the input of slaughter the elements of animal, butcher and others. In the generic space, we can come to the similarities between the two inputs that is the action taken towards a living by a sharp tool. But the purpose of the operation is to cure and the purpose of the slaughter is to kill. Therefore, we could come to the conclusion that "The surgeon is incapable." The combination of CMT and CBT will offer us a better understanding of language and concept to a larger extent. In the following parts, the theories will be employed to the study of metaphors in the novel Beloved.

\section{Metaphorical Analysis of Governing Image of Water in Beloved}

One of the salient features of Toni Morrison's novels is the abundance of significant images and metaphors with deep meanings which have been placed much weight on and widely appreciated. The metaphors are drawn from nature and the life of the black people. This part of the article aims to analyze one of the governing images - the water to explore the metaphorical meanings and the psychological foundations of these metaphors.

As an indispensible part in the African religion and culture, "water" is also a recurring image in the novel and the life of the characters is to some degree intertwined with water. According to Oxford English Dictionary, water is defined as the liquid of which seas, lakes, and rivers are composed, and which falls as rain and issues from springs. When pure, it is transparent, colorless (except as seen in large quantity, when it has a blue tint), tasteless, and inodorous. In reality, water is an important element of earth and our life. In literature, it always stands for power, destruction and rebirth. The metaphorical analysis of this element in nature is not only central in understanding the characters' attempts to live a better life, but also the way Morrison tries to tell her story. In the novel, water makes its appearance in different forms such as water itself, rain and river and Toni Morrison employs the image of water and the power it possesses to explore the mental process and personal experience of black people as well as unfold the black's history. This part of the article aims to probe into the metaphorical meanings of the above-mentioned forms of water, which contributes to the themes of the novel.

\subsection{Water and Memory}

One salient nature of water is its fluidity with no boundaries and no shape; therefore, one can't exactly know where it begins and where it ends. On the one hand, it is a symbol of freedom which keeps flowing day and night towards any direction as it wants. On the other hand, it is vulnerable to lose control of itself and bring unexpected and unconscious results. According to psychologists, water is a symbol of unconsciousness, which comes from the unknown levels in one's mind. This quality of water is consistent with the mind of people which keeps moving, even losing control of itself. Toni Morrison employs the image of water to reveal the state of mind of the characters and the recall is always interwoven with the flowing of water. The structure of the novel is loose and irregular with repeated monologues threading through it, which will make it hard to understand without a close analysis of the unconsciousness of mind. The image of water shares similarities with one's mental process and provides us a good tool to catch on the themes of the novel.

All the slaves have an unbearable past of torture and pain which they are reluctant to face. Morrison once claims that: "Modern life begins with slavery."(Gilroy, 1993a) Since being plunged into slavery, African Americans have been struggling with confusion, alienation of community, loss of themselves, and all the emotional, psychological, social, and traumas. For Sethe, "she worked hard to remember as close as to nothing as was safe.", "Every mention of her past life hurt. Everything in it was painful or lost." (Beloved, 2011, p. 58). The situation is true with Paul D, Baby Suggs and others. At the beginning of the novel, the motion of water triggers her memory of the life in Sweet Home. When "Sethe rushes toward water,... sopping the chamomile away with pump water and rags, her mind fixed on getting every last bit of sap off,...with the plash of water, there was sweet home rolling, rolling, rolling out before her eyes, and although there was not a leaf on that farm that did not make her want to scream, it rolled itself out before her in shameless beauty." (Beloved, 2011, p. 6) This part is the description of Sethe's involuntarily recall. The flowing water not only brushes away the dirt, but also brings her mind back to the past and with the brushing of water, the past only gets clearer and clearer. Even though Sethe and her companions live a free life now, the terror is still hidden in their memory or in other words, the stream of their consciousness, which will emerge or even burst out at any time, just like the flooding of water. Besides the memory in Sweet Home, what tortures Sethe most is her infanticide in 124, the unbearable pains of which are buried in the stream of her soul. Sethe could not control her memory, just like could not control water. Memory is immortal, just like the endlessness of water. Whenever the infanticide is mentioned, the memory floods and the pains nearly drown her. Though she insists that it is out of "thick love" (Beloved, 1987, p. 164), she begs forgiveness from her little daughter and at last she successfully achieved her rebirth. In 124, when Sethe and 
Paul D reunited, their individual yet simultaneous memory of the traumas in the Sweet Home emerges again and again, "No misery, no regret, no hateful picture too rotten to accept? Like a greedy child it snatched up everything. Just once, could it say, No thank you? I just ate and can't hold another bite?" (Beloved, 2011, p. 70). The memories of them merged like water and produced a devastating effect on them which they could not find a place to hide. In the two inputs water and memory, what we can extract the similarities between them is flowing and free. Based on the projections, we can conclude the generic space: the nature and mode of movement. In the blend memory, like water flows freely, the past memory of the slaves and the pains of slavery can occur to them unexpectedly.

\subsection{Rain and Emancipation}

The image of rain often makes its appearance in literature works and is closely related with cognitive modes of people's mind. According to religious ceremonies, there are many forms of baptism, namely, baptism of water, baptism of fire and baptism of blood. In different religions, water plays an important role. Water appears for 442 times in the new international version of Bible and Peter even claims that the world is formed out of water and by water. Many cases can prove the purifying power of water. In Bible, when the degeneration of human being is intolerable, God orders rain to wash away the sin and evil of human being. The rain pours down for 40 days and floods everything only leaving Noah's Arc survived. Being based on the Bible, rain in Toni Morrison's novels is embedded with rich religious meanings and the function of the image of rain is played to full. Due to its quality of washing, rain is identified with destruction. At the same time, rain also brings hope and beginning of new life. The cognitive process of the relationship between rain and its metaphorical meanings are entrenched and conventional after many years, which makes the process inconceivable. And the analysis of the nature of this process will reveal the hidden meanings of the image of rain. In a world "the only bad luck is white folks" (Beloved, 1987, p. 89), when the torture of slavery is unbearable, rain is needed to wash away the malfeasance and demolish the old system. In the novel, the rain pours down for more than one month and "Georgia seems to be sliding, melting away." The whole place is lifeless. "Cypress, yellow poplar, ash and palmetto drooped, the doves were nowhere in sight, the salamanders were gone." (Beloved, 2011, p. 109). Surrounded by the outrageous rain, the 46 chained up black slaves seize the opportunity to escape from Alfred and the nightmare of past life-hard work like animals, cries of women, suffering from the whippings and frequent threats of death. It is a rain of destruction and all the evils are put to an end for the 46 men, just like baptism, Paul D regains his freedom and begins new life. As described in the novel, "The flood rains of a month ago had turned everything to steam and blossoms." (Beloved, 2011, p. 112). One common nature of rain and emancipation is their violence, the old world is smashed in the violence and the only way to defeat violence is by another kind of violence. Paul $\mathrm{D}$ wins his freedom from his own effort through the rain. Black people can achieve emancipation only by struggle of their own against the oppression.

\subsection{River and History}

Life originates from water and river nurtures human being and their culture. Human beings depend on river and draw power from river. There is no exception that in every ancient culture there is a "mother river". The close relationship between river and black people can date back to the ancient Nile, Congo River and Euphrates and black people usually pay great homage to rivers. There are tranquil flows and torrents in river while there are ups and downs in history. Every part of history is to some extent related to the significant meanings of river. For African Americans in the 19th century, the river of Ohio means life and redemption. "The Ohio River has historically represented freedom...The northern part of the state had underground railway stations and a history of black people escaping into Canada, but the southern part of the state is as much Kentucky as there is, complete with cross burnings. Ohio is a curious juxtaposition of what was ideal in this country and what was base." (Tate, 1985, p. 119). Most escaped slaves choose Ohio River to the north where the slavery is abolished and they could regain their identity as free ones. Ohio offers them a sense of security and a gleam of hope to survive. At the same time, it serves as the background of many plots and correlates the destinies of slaves with their history. The image of river accompanies the escape of Sethe and sends her to the new life. After stumbling in wild for 28 days, the pregnant Sethe comes to the bank of Ohio. "Sethe was looking at one mile of dark water, which would have to be split with one oar in a useless boat against a current dedicated to the Mississippi hundreds of miles away." (Beloved, 2011, p. 83). In this place, she find the sense of home and inner peace. When "Her own water broke loose to join it (the river)." (Beloved, 2011, p. 83), her life as well as the life of the new-born baby Denver is blending with the river. It is a line between life and death and it is a turning point in the history. She wakes up from the dream of death on the other side of the river and "she walked a way downriver and then stood gazing the glimmering water." (Beloved, 2011, p. 90). The tribulation of the past is brought away by the rushing river and her nightmare of death and hurt is also washed away by it. Breaking away from an 
animal-like life, Sethe achieves her rebirth as a woman, a wife and a mother. Other black characters have similar experience with Sethe. Baby Suggs, Paul D and Denver all begin their new life on "the other side" of the river, which is the result of the turning of history. Beloved, the incarnation of life and death, is "associated throughout the novel with water and other liquids: urine, sweat, amniotic fluid, the salt water both of Middle Passage and of tears, the salt water that rusts iron and creates the flakes of rust that fall away from Paul D's tobacco tin heart when he makes love to Beloved and his tinned heart opens up. She is the drown self, the wounded child of the men in this novel, as well as the women." (Lynda, 2001). As an incarnate of ghost and human being, Beloved entered the novel when she "walked out of the water" (Beloved, 2011, p. 50) returns to the creek from which she came: "By and by all trace is gone, and what is forgotten is not only the footprints but the water too and what is down there." (Beloved, 2011, p. 275) It is mentioned in the previous chapter that Beloved is a bridge between the world of death and the world of life; she is also the path connecting the past and future. Therefore, her intertwining with river and creek is in every way intertwining with the black history. According to African religion, water refers to the afterlife. Beloved regains her body and comes to the world of living with the history that Sethe and her companions are reluctant to face. She is not only the daughter who is killed to death by her own mother and come back to revenge; she is the collective image of all the black women. When "The thaw was complete Beloved gazed at her gazing face, rippling, folding, spreading, disappearing into the leaves below....touched the rocking faces with her own."(Beloved, 2011, p. 241), the river mirrors the past of her and her fellowmen; the face in the river is also the truth of the history. By touching the face, she identifies herself with the continuous nature of the river, with the river, she delves into the past.

\section{Connections and Coherence of the Metaphors}

The novel is alive with metaphors that are closely and systematically related to form a harmonious semantic network and provides us an opportunity to probe into the significant themes of it. Analyzing from the perspective of CMT and CBT, there are similarities between the nature and human emotions; and human emotions can find their projection in the nature. The images of water are common in nature, while in the novel they are far from being simply emotionless objects. "Like an iceberg, the words on the surface are just a corner of the whole iceberg below and the related semantic network is hidden." (Ding, 2000). Water always takes an important position in literature and flows throughout this novel as well as the life of the black. Its different forms it reveals various metaphorical meanings. Water, rain and river are respectively associated with memory, rebirth and history. The irremovable memory flows like water and floods to every part of the black's hearts unconsciously. Due to its quality of washing, rain is identified with destruction and restoration. In the novel, rain destroys the old order of the society and brings the physical as well as spiritual redemption to the slaves. River gives birth to and nurtures human being with its origin in the ancient times. The quality of river that sometimes flows slowly and sometimes rushes violently is in every way similar to the emotions of people which can either keep calm or burst out. River witnesses challenges and overcomes obstacles just like the black experience the ups and downs of history. River has a history which is not only a history of water but also the history of people. People's emotion is expressed through the flowing of river and river witness the experience of people.

\section{Conclusion}

As a great African-American writer, Toni Morrison is devoted to writing the experience and exploring the mental process of black people. Her outstanding writing skills and deep insights also win widespread compliments. Beloved is written at the peak of Toni Morrison's creating power and offers us the best expression of her extraordinary literary achievement and deep social concerns.

Language is an expression of the mind and mind influences our language. Therefore, studying language from the level of mind is more persuasive and reasonable. Cognitive literary criticism is composed of a wide variety of interpretive strategies and metaphorical explanation of language in this field has aroused wide attention. Traditional way to appreciate the metaphors in the literature work is limited to its rhetoric and artistic function. Compared with the traditional methods, metaphorical analysis demonstrates the models of mental operations of writers Metaphorical language is a salient feature of the novel and its plots are developed on the basis of these metaphors. This article aims to study these metaphors from the perspective of the way of thinking based on the conceptual metaphor theory and conceptual blending theory. Through exploring the metaphorical meanings of the governing images of water and analyzing the connections between them, we could construct mental spaces of the images and the network, thus fully understanding the themes of the novel, that is the evil of slavery brings physical and psychological traumas to the black slaves while they still succeed in achieving self-redemption and constructing their self-identities.

This article is only a tentative attempt to appreciate literary works through cognitive linguistics and it is hoped 
that it will contribute a new perspective to the interpretation of Toni Morrison's Beloved.

\section{References}

Bell, H. (1983). Keeping a Hold on Life: Reading Toni Morrison's Fiction. Santa Cruz, CA: University of California

Ding, F.-S. (2000). A Study on Metaphor. Shanghai: Shanghai Foreign Language Education Press.

Fauconnier, G., \& Turner, M. (1996). Blending as A Central Process of Grammar. In G. Adele (Ed.), Conceptual structure, Discourse and Language. Stanford: CSLI Publications.

Gilroy, P. (1993). The Black Atlantic: Modernity and Double Consciousness. Boston, MA: Harvard University Press

Lakoff, G., \& Johnson, M. (1980). Metaphors We Live by. Chicago: University of Chicago Press.

Lynda, K. (2001). "To be loved and Cry Shame": A Psychological Reading of Toni Morrison's Beloved. Storrs, CT: University of Connecticut.

McKay, N. (1988) Critical Essays On Toni Morrison. Boston, MA: G.K. Hal 1 \& Co.

Morrison, T. (1987). Beloved, New York: Knopf.

Morrison, T. (2011). Beloved, New York: Random House.

Tate, C. (1985). “Toni Morrison” Black Women Writers at Work. New York, NY: Continuum.

\section{Copyrights}

Copyright for this article is retained by the author(s), with first publication rights granted to the journal.

This is an open-access article distributed under the terms and conditions of the Creative Commons Attribution license (http://creativecommons.org/licenses/by/3.0/). 